\title{
Malignant brenner tumour of ovary: a case report and review of literature
}

\author{
Santosh Kumar Dora, Debashish Dash, Snehadarshini Karanth, Kishore Chandra Mahapatra
}

\author{
Correspondence: Dr Santosh Kumar Dora, Assistant Professor, Department of Obstetrics and \\ Gynaecology, VIMSAR, Burla, Odisha; Email - santoshdora1@gmail.com
}

Distributed under Creative Commons Attribution-Share Alike 4.0 International.

\begin{abstract}
Brenner tumours are rare epithelial tumour of ovary. It was first described by Frit Brenner in 1907. In this case report, a 50 year old lady came to hospital with pain abdomen for 1 week with the bilateral palpable mass in both iliac fossa on per abdominal examination. Her CA 125 was 525 mU/L and on CT scan bilateral heterogeneous mass with cystic area was seen. Total abdominal hysterectomy with bilateral removal of ovarian mass along with fallopian tube, bilateral pelvic lymphadenectomy and infracolic omentectomy was done. Histopathological report revealed malignant brenner tumour. She is presently on combined chemotherapy of carboplatin and paclitaxel.
\end{abstract}

Keywords: Epithelial ovarian tumour, brenner tumour, carcinoma ovary.

Brenner tumour is a relatively uncommon epithelial tumor of the ovary. It constitutes about $1.5 \%$ of the total ovarian tumor ${ }^{1}$. Out of this malignant brenner tumour (MBT) constitute only $1 \%$. It has got a predilection for postmenopausal women. It has to be differentiated from the more common transitional cell carcinoma as it carries a good prognosis compare to the transitional cell carcinoma. But due to rarity of the malignant brenner tumour, its management is based on the experiences from the isolated small case series and case reports. Here we present a case of brenner tumor. It's important to discuss this case as very few case reports have been published till date and there is limited experience available for its management in world literature.

\section{Case report}

A 50 year old lady with the chief complains of pain abdomen for 1 week was referred to Veer Surendra Sai Institute of Medical Science and Research (VIMSAR), Burla, Odisha hospital 3 month back. VIMSAR is a leading medical college of western Odisha catering patients from three nearby states (Jharkhand, Chattishgarh, Odisha). She didn't have any other symptom except pain abdomen. Her general examination revealed no abnormality. On per abdominal examination she didn't have any ascites. A bilateral palpable mass of size $8 \times 10 \mathrm{~cm}$ and $8 \times 6 \mathrm{~cm}$ felt on both the iliac fossa. On per speculum examination cervix and vagina were appearing normal. On pelvic examination uterus was normal size. Both the masses were felt separately from the uterus. The masses were mobile, cystic and non-tender. There was

Received: $8^{\text {th }}$ October 2016. Accepted: $5^{\text {th }}$ May 2017.

Dora SK, Dash D, Karanth S, Mahapatra KC. Malignant brenner tumour of ovary: a case report and review of literature. The New Indian Journal of OBGYN. 2017; 4(1): 94-6 
no nodularity on pouch of douglas. Investigations were done. Her CA 125 was $525 \mathrm{mU} / \mathrm{L}$ (normal $<35 \mathrm{mU} / \mathrm{L}$ ). On USG there were bilateral cystic mass with solid area and internal septation seen. On CT scan bilateral heterogeneous mass with cystic area were seen. There was no ascites or any evidence of metastatic tumour deposit. On laparotomy there was no ascites. On systematic exploration of abdomen revealed no metastasis. A mass of size $8 \times 10 \mathrm{~cm}$ and $8 \times 6 \mathrm{~cm}$ in right and left ovary were seen. We did total abdominal hysterectomy bilateral removal ovarian mass along with removal of the fallopian tube, bilateral pelvic lymphadenectomy and infracolic omentectomy. On histopathology report reveals brnner tumour of ovary. She is now on combined chemotherapy carboplatin and paclitaxel. She will receive total 6 cycle of above mentioned chemotherapy. Presently she is doing well.

\section{Discussion}

The first case of malignant brenner tumour (MBT) was reported by Von Numers in 1945. But due to its rarity only few case reports are reported till today. Hull and Cambell proposed criteria for the diagnosis of this rare entity. We have labelled our case according to these criteria. The criteria proposed by them are as follows (i) Frankly malignant histopathological features must be present, (ii) There must be intimate association between the malignant element and a benign brenner tumour, (iii) Mucinous cystadenoma should preferably be absent or must be well separated from both the benign and the malignant Brenner tumors, and (iv) Stromal invasion by epithelial elements of the MBT must be demonstrated. ${ }^{2}$ Most of the MBT in stage I are unilateral only in $16 \%$ of cases bilaterality is seen.

Most of the patient presented in stage I (64\%) with a mean diameter of $10 \mathrm{~cm}$. We have similar presentation except early age of diagnosis compare to the literature, but it may be due to a coincidence. Despite extensive use of CT scan and USG, it fails to demonstrate the utility of USG and CT scan for the diagnosis of MBT as these tumours have nonspecific radiological findings. ${ }^{3}$ As in all other epithelial ovarian tumours cyto-reductive surgery is the main stay treatment.
There is no consensus regarding the standard chemotherapy due to its rarity. ZhensongYue et al (2016) in their review of 10 cases over 32 years found various chemotherapy regimens used from time to time. ${ }^{4}$ Similarly in 2015 Ji-Hyun Han et al describes 10 cases of MBT over a period of 22 years found patients have received different chemotherapy protocol. ${ }^{5}$ Due to the rarity of the MBT it is difficult to formulate a standard chemotherapy protocol for it. We have used carboplatin and paclitaxel as the standard protocol for epithelial ovarian tumour. Besides this gemcitabine (G); gemcitabine, taxol, carboplatin(GTC); hycamtine, carboplatin(HC); hycamtine,cisplatin (HP), docetaxele,cisplatin (DP); carboplatin, paclitaxel (TP) regimen have been used in the past. An effective tumor marker will help in the follow up and detection of early recurrence. But unfortunately we didn't have any sensitive tumor marker for the MBT. In some patient CA 125 may be raised but it has got no correlation with the stage or the tumour burden ${ }^{5}$. In few patients with MBT, CA125, CA72-4, SCC, and CA72-4 are raised. But due to its infrequent existence more cases are required to validate this findings. ${ }^{6}$

\section{Conclusion}

Malignant Brenner tumour of the ovary is a rare entity. But it is to be differentiated from the more common transitional cell carcinoma of ovary. As prognosis of the two malignancies are different. Till now there is no standard treatment protocol available due to its rarity. So this case signifies the importance of managing such cases in a tertiary care cancer hospital where there will be experiences in managing such type of rare cases will be available.

\section{Conflict of interest: None. Disclaimer: Nil.}

\section{References}

1.Gezginç K, Karatayli R, Yazici F, Acar A, Çelik Ç, Çapar M, et al. Malignant Brenner tumor of the ovary: analysis of 13 cases. Int J ClinOncol. 2012; 17(4): 324 - 9.

2.Hull MG, Campbell GR. The malignant Brenner tumor. Obstet Gynecol. 1973; 42(4): 527-34. 
3. Moon WJ, Koh BH, Kim SK, Kim YS, Rhim HC, Cho $\mathrm{OK}$, et al. Brenner tumor of the ovary: CT and MR

findings. J Comput Assist Tomogr. 2000; 24(1): 72-6.

4.Zhensong Y, Tongguo S, Zhanyu P, Wenfeng C,

Zhuchen Y, Zhansheng J, et al. Malignant Brenner tumour of the ovary: clinical, pathological and demographic analyses of 10 cases. Int J Clin Exp Pathol. 2016; 9(5): 5642-46.

5.Han JH, Kim DY, Lee SW, Park JY, Kim JH, Kim YM, et al. Intensive systemic chemotherapy is effective against recurrent malignant Brenner tumour of the ovary: An analysis of 10 cases within a single center. Taiwanese Journal of Obstetrics and Gynecology. 2015; 54(2): 17882.

6.Yamamoto R, Fujita M, Kuwabara M, Sogame M, Ebina Y, Sakuragi N, et al. Malignant Brenner tumor of the ovary and tumor markers: case reports. Jpn J Clin Oncol. 1999; 29(6): 308-13.

\section{Santosh Kumar Dora ${ }^{1}$, Debashish Dash ${ }^{2}$, Snehadarshini Karanth ${ }^{3}$, Kishore Chandra Mahapatra $^{4}$}

${ }^{1}$ Assistant Professor, Department of Obstetrics and Gynaecology; ${ }^{2}$ Junior Resident, Department of Obstetrics and Gynaecology; ${ }^{3}$ Doctor, Department of obstetrics and Gynaecology; ${ }^{4}$ Senior Resident, Department of Obstetrics and Gynaecology, VIMSAR, Burla, Sambalpur,Odisha, India. 